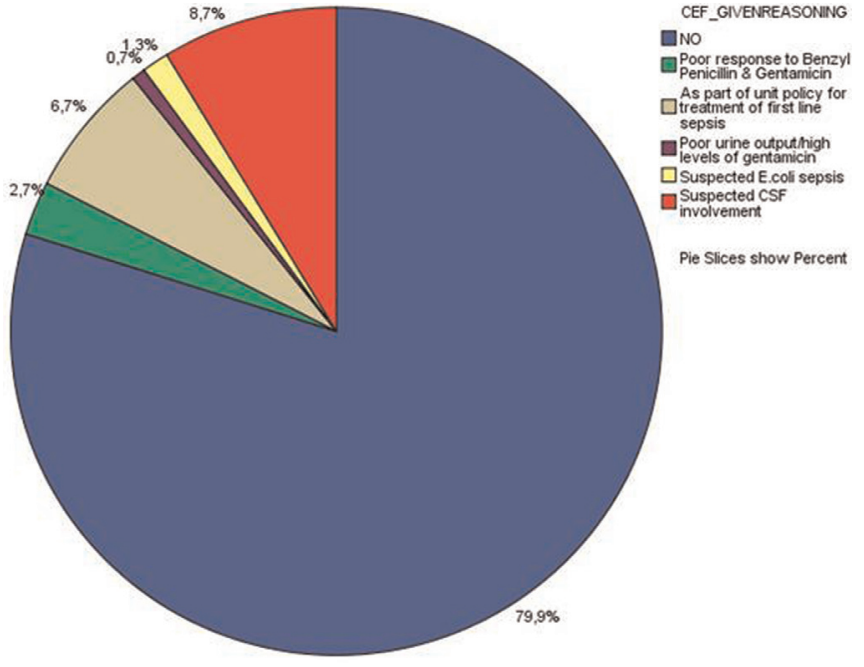

Abstract PS-216 Figure 2

Background Clinical practice within the network is facilitated by a regional guideline and a relevant clinical guidance tool from the National Institute for Health and Clinical Excellence (NICE149, August 2012).

Methods Prospective study from September 2012 until May 2013. 17 participating neonatal units within the network. 10 cases from each unit were included. These referred to term or preterm infants who required intravenous antibiotics for suspected or confirmed early onset sepsis with a minimum length of stay of 10 days. The data were analysed using SPSS 17.0.

Results 15 units participated. 149 babies were recruited with a mean gestational age of $32+2$ weeks. $91.3 \%$ of babies received intravenous benzyl penicillin and gentamicin as first line treatment. In $25 \%$ of cases there were prescribing issues regarding gentamicin. $20.1 \%$ received cefotaxime. $19.5 \%$ of babies underwent a lumbar puncture. $17.5 \%$ of babies received antifungal agents. In $15.4 \%$ of which as treatment.

Conclusions The overall outcome was positive with prompt recognition of risk factors and initiation of treatment across all units. This unified policy promotes good quality of care. However, the percentage of prescribing issues regarding gentamicin was worryingly high. Hence, further studies and review of literature are required to evaluate the efficiency of our practice and to establish alternative choice of antibiotics.

\section{PS-217 IMPACT OF THE NEW ALGORITHM FOR MANAGEMENT OF NEWBORNS WITH RESPECT TO RISK FOR EARLY-ONSET GBS DISEASE}

M García Díaz, T González Martínez, V García González, J GonzáLez García, B Fernández Martinez, C Pérez Mendez. Servicio de Pediatria, Hospital de Cabueñes, Gijon, Spain

\subsection{6/archdischild-2014-307384.516}

Background Guidelines for the prevention of perinatal group B streptococcal (GBS) disease were updated in 2010, including a revised algorithm for management of newborns with respect to risk for early-onset GBS disease (EOD-GBS).

Aim To know the impact of this new algorithm on EOD-GBS evaluations, hospital admissions, and detection of EOD-GBS cases in a newborn unit.

Methods Retrospective cohort study of infants of GBS-colonised mothers born at $\geq 36$ weeks gestational age in two periods of time: from July to December 2010, and from July to December
2012. The following variables were analysed: gender, gestational age, chorioamnionitis, indication for and prescription of antibiotics to the mother, EOD-GBS evaluations, infant admission and outcome. Continuous data were compared by using $t$ test; discrete data using chi square. Preventable fraction in the exposed $\left(\mathrm{Pf}_{\mathrm{e}}\right)$ was used to quantify the impact or the new algorithm.

Results One hundred and fifty-two neonates were included in 2010 and 130 in 2012. No significant differences between both groups were found regarding gender, gestational age, chorioamnionitis, obstetric care and antibiotic prophylaxis received by mothers. There were no cases of GBS infection in both periods. The new algorithm avoided $88 \%$ evaluations in EOD-GBS screening from 2010 to $2012\left(\mathrm{Pf}_{\mathrm{e}}=0.88,95 \%\right.$ confidence interval [CI]: 0.39-0.96). The number of infants admitted for suspected EOD-GBS was reduced by $48.1 \%\left(\mathrm{Pf}_{\mathrm{e}}: 0.481,95 \% \mathrm{CI}:-0.648-0.864\right)$. Conclusions Implementation of the 2010 algorithm resulted in a decrease of EOD-GBS evaluations and the number of newborn admissions for suspected sepsis.

\section{PS-218 DEVELOPING A SAFER DOSING REGIMEN OF AMIKACIN IN PRETERM INFANTS}

${ }^{1}$ SS Pereira, ${ }^{2}$ ST Kempley, ${ }^{1}$ AK Sinha. ${ }^{1}$ Department of Neonatology, Royal London Hospital, London, UK; ${ }^{2}$ Department of Neonatology, Barts and the London School of Medicine and Dentistry Queen Mary University of London, London, UK

\subsection{6/archdischild-2014-307384.517}

Background and aims Aminoglycosides with penicillin are commonly used first line antimicrobials of choice to target early onset sepsis organisms (1). The concern about emergence of gentamicin resistant gram-negative organism has led neonatal units to switch to Amikacin (2). The current British National formulary $(\mathrm{BNFc})$ recommends a dose of $15 \mathrm{mg} / \mathrm{kg} /$ day even for preterm infants. The ideal dose of amikacin for use in preterm infants is not clearly defined. The aim of this study was to compare amikacin blood levels in preterm infants less than 32 weeks gestation receiving two dosage regimens.

Methods During initial six-month period infants received amikacin dose of $12 \mathrm{mg} / \mathrm{kg} /$ day (group 1) and subsequently after a change to $12 \mathrm{mg} / \mathrm{kg}$ every $36 \mathrm{~h}$ (group 2) at the neonatal unit over a four-month period at Royal London Hospital. Data was collected from the neonatal database, hospital records and drug chart. Study was approved by Clinical effectiveness unit and Chi-square tests used for analysis (SPSS v22).

Results

Conclusions Most preterm infants even on a lower dose of amikacin than currently recommended by BNFc develop a high

\section{Abstract PS-218 Table 1}

\begin{tabular}{|c|c|c|}
\hline & $\begin{array}{c}\text { Group 1(amikacin } \\
12 \mathrm{mg} / \mathrm{kg} / \mathrm{day})\end{array}$ & $\begin{array}{c}\text { Group } 2 \text { (amikacin } \\
12 \mathrm{mg} / \mathrm{kg} 36 \\
\text { hourly) }\end{array}$ \\
\hline $\mathbf{N}$ & 46 & 18 \\
\hline No of babies with high trough amikacin levels (\%) & $35(76)^{\star}$ & $6(33)^{\star}$ \\
\hline Mean gestation in weeks (SD) & $28.3(2.8)$ & $28.0(2.7)$ \\
\hline Mean Birth weight in grams (SD) & $1129(354)$ & $1020(360)$ \\
\hline Mean Creatinine (range) in micromol/L & $78(36-111)$ & $79(20-140)$ \\
\hline
\end{tabular}

